Available online at www.sserr.ro

Social Sciences and Education Research Review

(7) $2225-240(2020)$

ISSN 2393-1264

ISSN-L 2392-9863

\title{
ASPECTS OF EMOTIONAL ABUSE IN MIDDLE SCHOOL
}

\author{
Alina Maria BREAZ \\ Assoc. Professor, PhD, "Aurel Vlaicu University, Arad, Romania
}

\begin{abstract}
Psychological mistreatment, however harder to characterize and harder to recognize, goes with all types of youngster misuse and has pulverizing outcomes on its agreeable turn of events. Our investigation on 60 kids from the exercise center stage intended to feature the psychological mistreatment of offspring of this age and its potential outcomes. Through a guided meeting, the sorts of psychological mistreatment, its causes, the recurrence of misuse, its relationship with different kinds of misuse were followed. The acquired outcomes mirror a somewhat stressing circumstance, demonstrating that the guardians' confusions and mindsets persevere in their instructive style, which may influence the mystic equilibrium of the kid in a troublesome time of life, specifically that of pubescence. The advising work of the analyst or social associate of the gatherings engaged with types of psychological mistreatment (guardians and youngsters) can contribute not exclusively to improve the kid's circumstance, its mix into the age gathering and the expanding of school's exhibitions yet additionally to improve its relations with guardians and fraternity and in this manner to build its odds of an agreeable turn of events.
\end{abstract}

Keywords: abuse, children, performance. 


\section{Introduction}

In today's evolving contemporary society, we can still encounter behaviors or situations that require society's full intervention through accredited institutions and staff. These are cases where parents abuse or neglect children, or are unable to give them the sense of protection, safety, and affection they need.

Concerns about this area's research, child abuse is relatively recent (about 50 years) and are related to the name of C.H. Kempe (Kempe, Silverman, Stell, Siver, 1962), which draws society's attention to the need to realize that the general purpose of a generation are children who will perpetuate humanity.

Emotional abuse is the most difficult to define, of all forms of maltreatment and may occur in very different situations of life. In short, it can be defined as a chronic attitude or action of parents or other caregivers who harm or hinder the development of a child's self-image.

Emotional abuse has nothing to do with isolated rejection events, which can be found in the vast majority of families. In situations where they are distant and irritated, parents can overlook children's needs and focus only on their personal needs. The child can react with anger, disappointment or confusion. Emotional abuse involves a pattern of steady and stable behavior towards the child, a behavior that becomes a dominant feature of his life.Evil produced may go unnoticed because the scars are inward, but the consequences are more serious than any other form of abuse (Neamtu, 2016).

\section{Theoretical frame}

The grouping of various types of psychological mistreatment can be founded on the kind of circumstance the kid is exposed to. Practically speaking, a few circumstances are not unmistakable, being hard to separate from others comparative yet not with undertone of psychological mistreatment. 
A first sort of misuse is identified with youngsters who are adversely seen by their folks, once in a while even from the snapshot of their introduction to the world. They are uncovered, from the main long periods of life, to various levels of dismissal. Youngsters feel that something isn't right with them, that their folks believe them to be moronic, insidious or insane. They are disregarded, criticized, dismissed, seen as the principle cause of issues for guardians.

This type of misuse can go inseparably with actual maltreatment: here and there psychological mistreatment is the most impressive, at times actual maltreatment might be the prevailing one.

"Cinderella Syndrome" is another type of appearance of psychological mistreatment, usually experienced. The kid is uncovered for this situation not exclusively to the psychological mistreatment of guardians yet additionally to the siblings' maltreatment. Different siblings, who, because of the guardians' mentality, as of now feel shaky and experience the ill effects of persistent tension, pick as a method for mitigating their circumstance, the chance of being aligned with their folks, speaking to "the force". They will characterize their sister or sibling as a dumb, inconceivable youngster who is liable of all that occurs in the family.

Terrorizing the child through threats of punishment, leaving or chasing is another form of manifestation of emotional abuse. Threats create a state of anxiety that the child can handle with great difficulty. A number of researchers agree that the threats to separation are probably more detrimental than true separation.

\section{Recent literature}

Emotional abuse is different from the physical one because the abused person often does not realize this, and often the abuser is unaware of the gravity of his actions. Rohner (1980) uses the names of "parental rejection" and emotional abuse with the same meaning. "Parents who reject or subject children to emotional abuse are often those who do not like, do not accept or are against 
children (...). Rejection is manifested in the world in two main ways - on the one hand by indifference, and on the other by neglect. "(Rohner, Rohner 1980, p.193)

Another gathering of kids who are presented to psychological mistreatment are those whose guardians are brutal with one another. For a large number of these youngsters, encountering viciousness is to live in similar condo or home with their folks and furthermore to endure the outcomes of the disdain and aggression atmosphere between their folks and the remainder of the family. These kids live in a condition of tension and utilize their energy to deal with themselves and, now and again, oddly, even by their folks. They are compelled to assume liability in circumstances for which they are not yet experienced enough to manage them. There is without a doubt, next to no satisfaction or energy left to put resources into play, involved with other youngsters or in instructing. Kids who are seeing rehashed scenes of brutality among guardians regularly neglect to beat a horrendous scene when the second is appearing(Buzducea, 2010).

The circumstance of these youngsters can likewise be described as one of pretty much disregard by guardians. Their opportunities for family recognizable proof are restricted both in relating to the oppressive parent and in relating to the mishandled parent. Later on, youngsters' character issues identified with attention to their own worth, or explanation of sexual personality, can be found in these kids. Huge numbers of the youngsters coming from such families and set in kid insurance focuses can be discovered later in the police reports or in the records of mental medical clinics.

A specific classification is spoken to by youngsters whose guardians devour drugs or different substances. In such circumstances, youngsters effectively notice that grown-ups in their company are worried about their own reality, their own issues, and can at this point don't deal with them all things considered. A kid for the most part lives in nervousness and is presented to circumstances he can't comprehend. He sees that his folks can at this point don't 
deal with themselves and that they have lost control. Kids with separated from guardians are presented to psychological mistreatment. The youngster sees himself trapped in a persistent clash where the guardians blame one another and he is compelled to remove a portion of one of them. The youngster gets restless and has befuddled sentiments since he loses a parent without reserving the privilege to be troubled, ask or get help. The annoyance and give up all hope of the kid may not be communicated transparently, direct additionally getting discouraged and/troublesome. The separation cycle through which he is compelled to pass influences his binds with their family members in a negative manner for a long time(Adams, Dominelli, Payne, 2009).

The percentage of children who have been emotionally abused and who later arrive at adult psychiatric clinics may be quite high, but there is still little clear data on this issue. Probably, setting clear criteria for recognizing emotional abuse will increase the number of middle-class families that will appear as inappropriate child care.

Increasingly more typical is another type of disregard, in particular enthusiastic, which isn't really connected with actual disregard. Guardians are unequipped for participating in a passionate relationship with their own kid and are attempting to remunerate this by fulfilling critically material necessities. The consistent view is that absence of enthusiastic accessibility is the premise of all different parts of psychological mistreatment, albeit passionate disregard is difficult to see right away. (Bonchiș, 2004)

Disregard is one of the most noticeably awful types of abuse, since the parent doesn't mishandle the kid, yet basically couldn't care less it. Important, in not many cases, guardians know that they disregard their youngster. They're for the most part pardon is that they work more enthusiastically (and consequently are additionally missing at home) just to be in an ideal situation to their youngster and to have the option to offer them more. 


\section{Hypothesis}

The hypothesis from which we start is that emotional abuse is more common than official reports and statistics show.

\section{Studied lot}

We took the study, a group of 60 pupils from the middle age group, aged between 10 and 14 years (see Table 1 )

\section{Table 1. Distribution by age group of children under study}

\begin{tabular}{|l|l|}
\hline Age group & Number \\
\hline $10-11$ years & 8 \\
\hline $11-12$ years & 12 \\
\hline $12-13$ years & 15 \\
\hline $13-14$ years & 25 \\
\hline Total & $\mathbf{6 0}$ \\
\hline
\end{tabular}

\section{Methodology}

We used a structured interview that we had with each child (Cojocaru, 2005). The questions of the interview tended to address the following aspects: the forms of emotional abuse, its frequency, the degree of association with physical abuse, the motivation of people using emotional abuse on children, the association with forms of abuse by other people.

\section{Results and discussions}

Generally, emotional abuse, though difficult to highlight and measure, leaves strong fingerprints on the child's personality, school performance and overall behavior. 
The most common forms of emotional abuse encountered in the study were swearing, threatening with physical punishment, and threatening to leave or chasing home (Table 2).

Table 2. Forms of emotional abuse encountered in the studied group

\begin{tabular}{|l|l|l|l|l|}
\hline $\begin{array}{l}\text { Forms of emotional } \\
\text { abuse }\end{array}$ & \multicolumn{5}{|l|}{ Frequency of abuse } \\
\hline & frequently & middle & rare & never \\
\hline swearing & 40 & 17 & 3 & - \\
\hline $\begin{array}{l}\text { threatening with physical } \\
\text { punishment }\end{array}$ & 32 & 11 & 16 & 1 \\
\hline $\begin{array}{l}\text { threatening to leave or } \\
\text { chasing home }\end{array}$ & 6 & 8 & 12 & 34 \\
\hline $\begin{array}{l}\text { He is witnessing domestic } \\
\text { violence }\end{array}$ & 28 & 18 & 6 & 8 \\
\hline Parents in divorce & 3 & - & - & 57 \\
\hline
\end{tabular}

The absolute in the table surpasses the quantity of kids considered on the grounds that one youngster might be the subject of different types of psychological mistreatment.

It can undoubtedly be seen that 42 of the kids go through deficient treatment. In actuality, among everybody, swearing is regularly normal, it is important for the standard jargon and is some of the time which isn't deficient in any sentence. In any case, for the youngsters who are preadolescent, whose affectability is expanded and whose character is delicate, are presently searching for models to follow and an arrangement of qualities to disguise, the results can be deplorable. They can go from bringing down confidence, making mistaken pictures of oneself and their own conceivable outcomes, receiving a disappointment and abdication demeanor, self-retreat and separation. 
School results will also be severely affected (due to concentration difficulties), and adaptability and integration will become ineffective. All this can bring about a change of attitude from colleagues and teachers, which will further aggravate the situation of the child.

A total of 32 children (more than half) are threatened with frequent beating, the rest more or less often and only one child has never been threatened. These findings tell us a lot about the methods of education that have already been established in many Romanian families. Even some broad-based expressions such as "beating is broken out of Heaven," "where mother strikes the child will grow," would be a justification for such treatment. Every people and country has its own expressions in this area, and in our country expressions "I beat you until you call your head," "I made you, I kill you," "I break your ears," etc. are often used by parents, although they do not really intend to do so.

With a less frequent appearance, but with a particularly strong impact on the child, is the chase away from home. It has been mentioned by a number of 14 children and has a strong emotional resonance on the child, who already imagines without the warmth of the home, lacking security and family support, without material and financial support. The survival instincts suggest that the child accept any conditions or compromises with the parents, in order to prevent the situation from materializing. He cannot realize that in most cases this type of threat is more rhetorical.

Another situation generating emotional abuse is that of children assisting, more or less frequently, at home violence scenes (28 cases). Physical or verbal violence between spouses has strong repercussions in the affective sphere of the child, experiencing feelings of anxiety, fear, sadness and unhappiness, with the consequences of self-closing, isolation, marked adaptation difficulties.

At last, one final circumstance that makes psychological mistreatment on kids is the place where guardians are separated. In the gathering we examined, we just had 3 cases. It is an especially unpleasant circumstance for the youngster, 
who sees his family breaking separated, aiding potential conversations and squabbles among guardians, discovers it has become a "haggling object" between guardians to figure out who they live with. In a word, his entire universe, which offered him warmth, security, comfort, uphold, was destroying. The kid regularly turns out to be automatically the primary motivation behind why the two life partners denounce and fight. He sees as long as he can remember up to that point, grieved, and it is especially hard for him to remove a portion of one parent against the other. Guardians, then again, excessively occupied with their own issues don't understand the effect and results of this situation on the agreeable improvement of the kid.

Often, emotional abuse is accompanied by effective physical abuse. Threats of beating and corporal punishment turn into a cruel reality. In Table 3 and Figure 1 it was shown the frequency of association of threats to the act itself.

Table 3. Frequency of association of emotional abuse with physical abuse

\begin{tabular}{|l|l|}
\hline association frequency & number \\
\hline frequently & 18 \\
\hline middle & 2 \\
\hline rare & 30 \\
\hline never & 10 \\
\hline Total & $\mathbf{6 0}$ \\
\hline
\end{tabular}

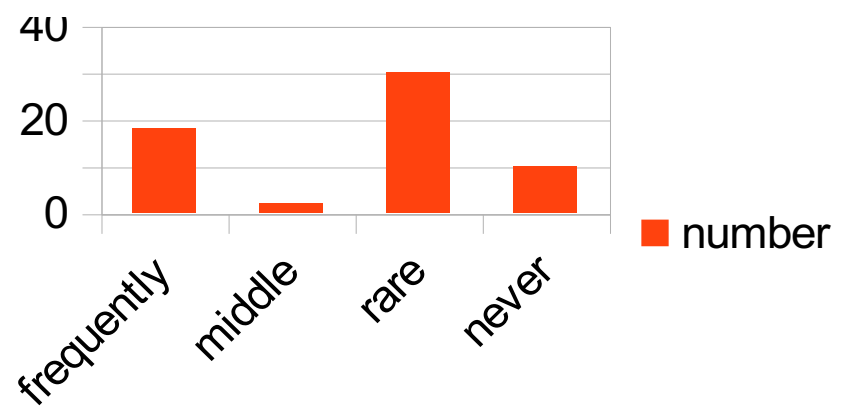

Figure1. Frequencyof association of emotional abuse with physical abuse 
For 18 children, the threat of beating turns into reality quite often. Psycho-trauma is double because we have, besides physical pain, also the moral pain, expressed by the shame of colleagues, due to the traces on their body. This is accompanied by feelings of inferiority and futility (he could not thank his parents, he is not good at anything), as well as feelings of humiliation and suppressed revolt. In this situation, the child can see different ways of reacting: accepting everything with obedience (resulting in a weak, humble person, fearful of the authority of others), gathering dissatisfaction and rebellion itself until adolescence, when all will be able to avenge and be able to "revenge". Of course, these two ways of reacting are the extremes, with a wide range of possibilities that the child can call, but unfortunately each choice will be influenced by the events that took place in childhood.

The causes that lead parents to apply, consciously or unconsciously, such methods of educating the child are multiple. In Table 4 we tried to synthesize them.

The total number exceeds the limit of 60 , because in many cases the reasons are associated, intertwine and we cannot speak of a single reason, taken alone.

Most circumstances allude to purported "minor" thought processes (defiance, whimsicalness) that would not need the utilization of such radical measures, communicated through language or conduct. We are battling here, with correspondence troubles that exist in the family, or some correspondence obstructions that can't be survived. It is more useful to disclose the circumstance to the youngster, to show its positive and negative parts of it, with the results that follow, than to begin undermining the kid without indicating him where he wasn't right.

Table 4 . The motivation of using forms of emotional abuse

\begin{tabular}{|l|l|}
\hline The motivation invoked by parents & Number \\
\hline Disobedience & 35 \\
\hline
\end{tabular}




\begin{tabular}{|l|l|}
\hline Naughtiness & 40 \\
\hline Absences from home & 20 \\
\hline Absences from school & 22 \\
\hline Theft from parents & 3 \\
\hline $\begin{array}{l}\text { Aggressive conduct at school that requires the } \\
\text { presence of parents }\end{array}$ & 18 \\
\hline $\begin{array}{l}\text { Battle with colleagues or other neighboring } \\
\text { children }\end{array}$ & 6 \\
\hline
\end{tabular}

Not all guardians comprehend, or need more time, that a conversation with the youngster, "from individual to individual," has preferable and enduring impacts over a danger or discipline, even merited. Being treated as a grown-up, the youngster will be thankful to guardians since they don't mortify him by beating him, he will be pleased to have the option to converse with them as a grown-up, increment his/her confidence and self-trust. What's more, through the conversation, the kid will know about their part in making such a circumstance, which is the obligation regarding the submitted deeds and why the guardians and, verifiably, the general public can't acknowledge such practices.

Often, children abused emotionally by their parents are treated the same way by their brothers, colleagues or teachers. Table 5 and figure 2 show these associations of emotional abuse.

Table 5. Associations of emotional abuse exercised by parents

\begin{tabular}{|l|l|}
\hline Associations & Number \\
\hline With emotional abuse from brothers & 25 \\
\hline With emotional abuse from colleagues & 30 \\
\hline With emotional abuse from teachers & 15 \\
\hline
\end{tabular}




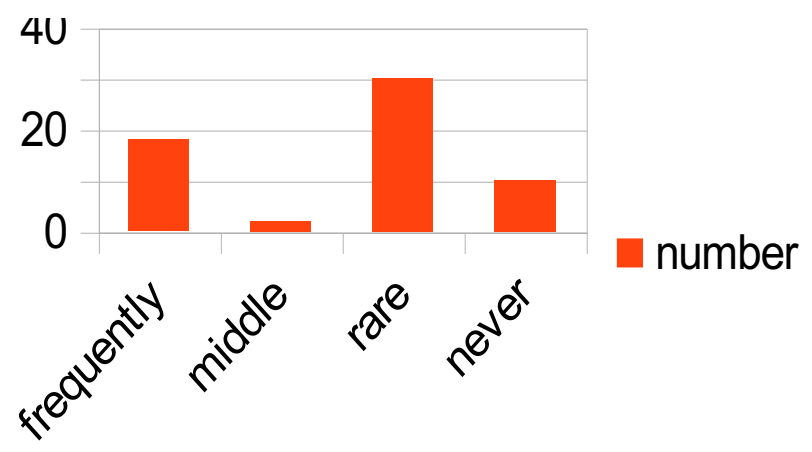

Figure 2. Associations of emotional abuse exercised by parents

We offer a similar comment as at the past tables: the absolute number surpasses the breaking point, on the grounds that the circumstances recorded in the table are frequently related. For instance, a kid might be exposed to psychological mistreatment by guardians, and yet is exposed to psychological mistreatment by partners and educators.

As a rule, these types of misuse interpenetrate and interrelate one another. A kid manhandled genuinely by his folks can be treated by siblings with dismiss, detachment, undermined, or harmed. The family environment influences the conduct and mentalities of the youngster at school. He is more removed, more secluded, doesn't coordinate into the homeroom, doesn't set up companionship with different associates. These, in their turn, may misjudge these mentalities as one of predominance and refusal and treat them as needs be. This implies that they will make innumerable jokes and devilish jokes, wo exclude them in their conversations and exercises, will chuckle at him, accuse him unjustifiably before educators of a wide range of things, they will right away think about him " an unusual one. "

The school execution, which experiences the order of such circumstances, will tragically additionally impact the demeanor of the instructors. They will group him as a powerless, careless, disorderly understudy and will have negative mentalities towards him. They will compromise him with the call of the 
guardians, with the coregency, reiteration and even ejection. This will be thought about the conduct of the kid at home. This is the way the endless loop closes, which, to be "broken", requires the mediation of a certified individual in the field, for example, a therapist or social partner.Discussions with parents, their counseling, as well as discussions with the child can lead to the establishment of communication channels between the protagonists of the emotional abuse situation and overcoming any existing barriers of communication. Once the communication is restored, it is possible to specify the responsibilities of each person in the context of the given situation and to prefigure ways to solve the situation, which is beneficial for both children and parents. As a consequence, changing and improving the attitudes and behavior of the child will also lead to a change of optics from colleagues and, implicitly, teachers.

In this way, the work of the social worker contributes not only to improving the child's situation, his integration into the age group and increasing the school performance, but also to improving his / her relations with his / her parents and brotherhood, and thus to increase his / her chances of harmonious development.

\section{Conclusions}

The method of reacting of a kid to the abuse circumstances is altogether different, including bends of the impression of the climate, detachment responses, issues of enthusiastic reliance, separation, melancholy, psychosomatic responses, delay being developed, and sentiments of tension and blame.

To adapt to the evil treatment circumstance, the kid utilizes all his current assets to make certain endurance procedures that assist him with surviving or limit the impacts and significance of abuse. There are for the most part two sorts of regular use: Exaggerated variation procedure and overactive and damaging methodology. 
Our examination was directed on 60 kids from the exercise center through conversations dependent on a guided meeting that essentially centered around: the types of psychological mistreatment the kids were exposed to, the reasons for misuse, the recurrence of creation, and the relationship with circumstances maltreatment by others. (Roman, 2018)

With an expanded recurrence, it was experienced the accompanying kinds of psychological mistreatment: 40 are exposed to day by day wounds; 32 are compromised with the fight; 6 undermined with pursuing ceaselessly from home; 28 regularly witness aggressive behavior at home and 3 are caught in a parent's separation circumstance.

The relationship of psychological mistreatment with actual maltreatment is available: with a high recurrence in 18 cases; a center recurrence in 2 cases and a diminished recurrence in 30 cases. It ought to be noted, nonetheless, that in 10 cases this affiliation is absent.The motivation that parents invoke for the conscious or unconscious application of such treatments is: disobedience - 35 cases; mischief - 40 cases; absences from school or home - 20 cases, respectively 22 cases; aggressive conduct at school requiring the presence of parents - 18 cases.

Emotional abuse by parents on children is also associated with abuse from other people. So, we have associations with emotional abuse from the brothers in 25 cases, with emotional abuse from colleagues in 30 cases and with emotional abuse by teachers in 15 cases. We draw attention to the fact that a child can be abused by parents, brothers, colleagues or teachers in the same time.

As a consequence of emotional abuse, there is a delay in development, a drop in school performance, difficulties in classroom integration, depression, isolation, insomnia, and various somatic accusations. Referred and treated in time, they are improved and can be quickly recovered by the child.

Counseling work is necessary in these situations and will be done not only with the child but also with their parents and their social network, which can 
provide support and understanding in trying to solve the existing problem situation.

In this way, the work of the social worker contributes not only to improving the child's situation, its integration into the age group and increasing the school performance, but also to improving its relations with the parents and the brotherhood and thus increasing its chances of harmonious development. (Osiceanu, 2017)

\section{Acknowledgement}

We hereby state that the subjects involved in our research were informed about the voluntary character of participation in this research, about the understanding of information and of that fact that withdrawal from research is possible at any time without negative consequences upon the participant. The research complied with all ethical research standards, the research participants/participants`guardians giving their consent to participate in the research.

\section{REFERENCES}

Adams R., Dominelli L., Payne M. (2009). Critical Practice in Social Work. Second Ed., Hmpshire UK: Palgrave McMillan

Bonchiş, E. (2004). Psihologiavârstelor. Oradea: EdituraUniversității

Buzducea, D. (2010). Asistentasociala a grupurilor de risc. Iasi: EdituraPolirom

Cojocar, S. (2005). MetodeapreciatieinAsistentaSociala. Iasi: EdituraPolirom

Kempe, H.C., Silverman F.N., Steel B.F., Siver H.K., (1962). The Battered Child Syndrome. in American Medical Assessment, 1962, nr. 181, pp.17-24

Neamtu, G. (2016), (coord.). EnciclopediaAsistenteiSociale. Iasi: EdituraPolirom 
Osiceanu ME, Zaharescu Ş (2017). Occupational Therapy's Role in Recovery of Children with Mental Disabilities. Clin ExpPsychol3: 167. doi:10.4172/2471-2701.1000167

Osiceanu, ME, Zaharescu Ş (2017). Occupational Therapy's Role in Recovery of Children with Mental Disabilities. Clin ExpPsychol3: 167. doi:10.4172/2471-2701.1000167

Rohner, R.P., Rohner E.C. (1980). Antecedents and consequences of parental rejection. A theory of emotional abuse, in Child Abuse \& Neglect, 1980, nr. 4, pp. $189-198$

Roman A.F. (2018). Training master students for implementing the positive thinking programme in schools, Journal Plus Education, Vol. 20, No 2/2018, pp. 7-12

Roman, A.F. (2018). Training master students for implementing the positive thinkingprogramme in schools, Journal Plus Education, Vol. 20, No 2/2018, pp. 7-12 